\title{
VALIDATION OF SUPERVISOR EFFECTIVENESS DETERMINANTS FOR ENGINEERING TEAM-BASED ORGANISATIONS
}

\author{
P.N. Zincume ${ }^{1 *} \&$ J.L. Jooste ${ }^{1}$
}

\section{ARTICLE INFO}

\section{Article details virtually from 5-7 October 2020 . \\ Contact details \\ * Corresponding author philaniz@sun.ac.za \\ Author affiliations \\ 1 Department of Industrial Engineering, Stellenbosch}

Presented at the $31^{\text {st }}$ annual conference of the Southern African Institute for Industrial Engineering (SAIIE), held

Available online $\quad 11$ Nov 2020 University, South Africa

ORCID ${ }^{\circledR}$ identifiers

P.N Zincume

https://orcid.org/0000-0001-6041-8167

J.L. Jooste

https://orcid.org/0000-0003-2172-0480

DOI

http://dx.doi.org/10.7166/31-3-2430

\section{ABSTRACT}

The aim of this study was to identify, validate, and describe the determinants of supervisor effectiveness in the context of engineering team-based organisations. Five supervisor effectiveness determinants were identified through the use of the systematic literature review methodology, and validated using semi-structured interviews. This paper presents the validated supervisor effectiveness determinants using the input mediator output framework.

\section{OPSOMMING}

Die doel van hierdie studie was om die bepalende faktore van opsiener doeltreffendheid binne die konteks van ingenieurspan-gebaseerde organisasies te identifiseer, te valideer en te beskryf. Vyf opsienerdoeltreffendheid faktore is identifiseer deur die gebruik van 'n sistematiese literatuurstudie en gevalideer deur semi-gestruktureerde onderhoude. Die bepalende faktore word hier aangebied deur middel van die inset-bemiddelaar-uitset raamwerk.

\section{INTRODUCTION}

Team-based organisations (TBOs) are those in which teams are the performing units. More recently, organisations have acknowledged human capital and agility as the main drivers of organisational success, and have increasingly flattened their structures and transferred power downwards through the use of teambased systems. The use of team-based systems has continued to grow because of increasing global competition and technological changes [1].

In the engineering context, such as manufacturing organisations, the complexity of the processes followed and the products that are manufactured often require the use of work teams; and the effectiveness of these teams determines how successful the organisation will be [2]. Engineering organisations that are designed to employ the team-based model have been portrayed as being more agile and adaptable to the modern business environment, which is characterised by radical change and uncertainty [1].

An important factor in the designing of TBOs is the role of the management and leadership of teams. Many TBOs have moved their organisations towards being less hierarchical by removing lower-level managerial positions and decentralising authority to frontline staff. This has given rise to the prominence of so-called autonomous or self-managed teams. However, a recent study by Ingvaldsen and Benders [3] pointed out that the thinking that self-management replaces hierarchical management is flawed, as it ignores the crucial issues of managerial control and upward accountability. They argue that, even though the teams may be able to self-coordinate, the control of these teams requires upward accountability - hence the crucial role of team supervisors. Jassawalla and Sashittal [4] pointed out that team supervisors and leaders play a crucial role in high-collaboration teams by fostering communication, enhancing the teams' 
understanding of goals and strategies, developing the teams' process skills, and ensuring their access to information and resources.

Moran (1996), cited by Harris [5], found that 77 per cent of the failures of team initiatives were directly owing to the leaders or supervisors of teams. Supervisors represent a support system for teams, and have the ability to stifle a team's initiative. Significant scholarly work has been done to explore what managers (in general) can do to improve the effectiveness of teams. However, there is little scholarly work that focuses specifically on the effectiveness of supervisors in team-based organisations.

The effectiveness of supervisors has a direct impact on the morale, innovativeness, teamwork, and productivity of teams [6]. In a traditional hierarchical organisation, supervisors are tasked with overseeing subordinates; but in TBOs, team supervisors are part of the team. A wide range of organisations are designing and implementing team-based systems. This has attracted the attention of scholarly studies of teams in organisations and of how their effectiveness can be improved.

This study focuses on the effectiveness of team supervisors in team-based engineering organisations. Having noted the importance of team supervisor effectiveness in the context of team-based engineering organisations and the sparsity of literature that addresses this topic, this study seeks to identify, validate, and describe the determinants of supervisor effectiveness in the context of team-based engineering organisations. The engineering environments that the study draws from include construction, the power sector, transportation, chemical industries, manufacturing, and production.

\section{LITERATURE REVIEW}

Ever since the seminal work of Davis [7], the supervisor (also known as the foreman, team leader, etc.) has always been seen as the most critical and pressured point of the organisation, the one who closes the gap between higher management and the employees on the floor. More recently, Huo [8] described the supervisory role as the "meat in the sandwich", experiencing pressure from above and from below.

There is notable disagreement in the literature about the roles and responsibilities of supervisors. Some authors, such as Artz [9], seem to argue that supervisors are responsible for task-related responsibilities, and thus require technical competencies to be effective. The problem with this view is that it ignores recent developments in management roles. The role of a supervisor has evolved from task-related responsibilities to being a manager in their own right with administrative responsibilities and peoplemanagement duties. A timeline showing the evolution of the supervisor role is presented in Figure 1.

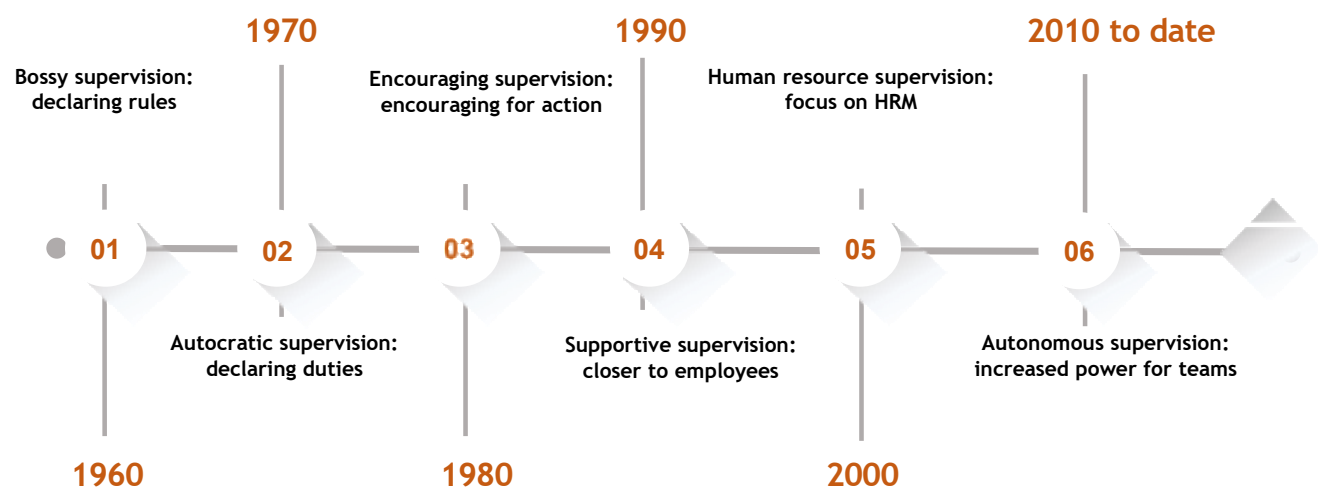

Figure 1: Evolution of the supervisor role

Traditionally, supervisors were employed literally to supervise other employees and to define the rules of work with a 'bossy' attitude. Subordinates were expected to stick to the hard rules, and the supervisors (known as foremen) were entrusted with the duties of ensuring that the rules were observed [10]. The decade of the 1970s ushered in an era of autocratic supervision: supervisors were employed to define duties in a one-directional sense. Receiving instructions from higher managers, supervisors were expected to drive these instructions down to subordinates, and were in charge of implementation and of activating employees [11].

In the 1980s, supervisors started focusing on creating a more affirmative environment. They became more encouraging to workers, and opened up opportunities for growth. Supervisors were also responsible for 
organising resources and motivating workers for action [12]. The supervisor/employee relationship grew even more in the 1990s, with supervisors working more closely with employees to clarify work objectives, and playing a more supportive and management role. This led to the rise of the human resource management (HRM) focus, which peaked in the 2000 s.

There is an overlap in the period from the year 2000 to the present, as the topic of HRM continues to dominate the supervisor literature. Supervisors still play a vital role in the implementation of HRM policies while supporting work teams and carrying out development discussions as part of a reward system [13]. Currently, supervisors are often expected to supervise from a distance, and to focus on building teams that are more autonomous, thus giving more power to teams and creating a sense of ownership. This has led to the widespread adoption of self-managing work teams [14]. However, supervisors are still the first line of management in most organisations. Giving power to teams in a participative sense has not absolved supervisors from the responsibility to influence work teams directly in the practices that occur in the workplace [15].

Even though the supervisory role has been explored in several academic studies, there have been very few that have attempted empirically to examine the determinants that lead to supervisor effectiveness, particularly in team-based engineering organisations. Therefore it is suggested that there is still a need, for the sake of theoretical and empirical development, to understand the supervisory role and its effectiveness determinants. The next section reviews the studies on the concept of effectiveness in teambased systems, and lays a foundation for what is meant by 'effectiveness' in the rest of the article.

\section{3}

DEFINING EFFECTIVENESS IN TEAM-BASED SYSTEMS

Traditionally, research into effectiveness in team-based systems has often followed the input-processoutput (I-P-O) framework proposed by McGrath [16] and later refined by Hackman [17], and shown in Figure 2. As pointed out by Dulebohn [18], the I-P-O is a useful theoretical framework, as it can be used to identify key inputs, processes, and outputs that are relevant to team effectiveness. The fundamental assumption underlying this framework is that input factors affect performance outcomes through the interaction process. In the I-P-O framework, team effectiveness is regarded as an outcome that is influenced by both the input and the output factors [17], [19].

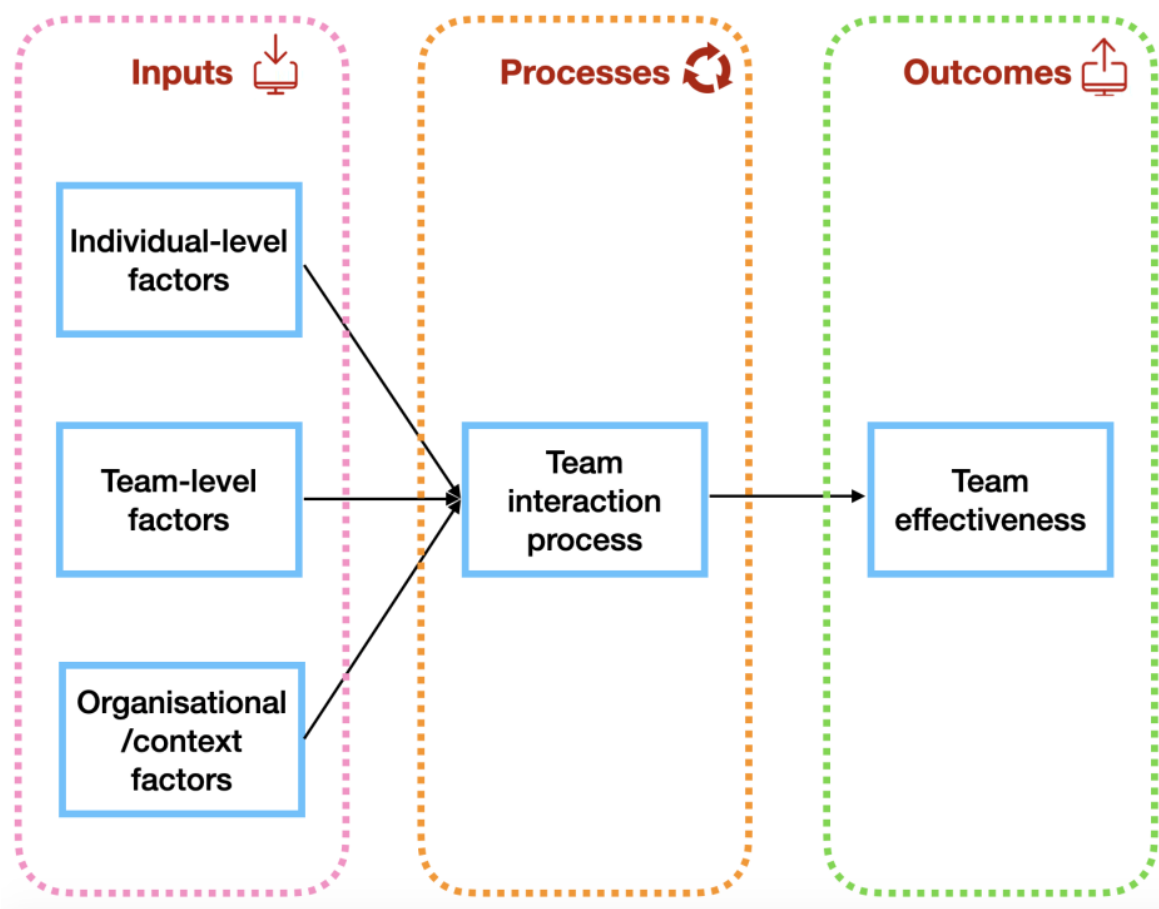

Figure 2: The I-P-O framework (adapted from McGrath [16]) 
'Inputs' (or 'antecedent factors') refers to factors that are prerequisites for enabling or even constraining members' interactions. They represent the various resources available to the team, both internally and externally at multiple levels [20]. An example of input factors might be individual-level factors such as competencies and personalities; team-level factors such as task structure and leader influences; and organisation-level factors such as reward structures and organisational design features [21]. These input factors, shown in the I-P-O framework, combine to drive the team processes [18].

'Processes' refers to the transformation of inputs into outcomes. They describe how members interact to accomplish a set task, and identify those activities that transform inputs into outcomes. This means that processes in the I-P-O framework mediate the relationship between inputs and outcomes. However, Ilgen [19] noted that many of the constructs identified by researchers as 'processes' are actually not processes at all; and so they proposed to replace the processes $(\mathrm{P})$ in the I-P-O framework with the term 'mediating mechanisms' or simply 'mediators' (M). 'Process' often refers specifically to a set of coordinated activities, while 'mediators' refers to factors that intervene in the transmission of inputs to outcomes or, expressed differently, as the variables that explain the observed relationship between the other variables. So this study uses the ' $M$ ' notation instead of ' $P$ ', since the dependent determinants are viewed as mediating the relationship between the independent determinants and the supervisor effectiveness construct.

'Outcomes' refers to the results and by-products of team activities, and include the three criteria of effectiveness in team-based systems; performance, satisfaction, and viability [21].

Research into effectiveness in team-based systems has often been guided by the I-P/M-O framework or its variations. Specifically in the engineering field, studies that have used this framework include that of Farris et al. [22], which investigated the critical success factors for human resource outcomes in Kaizen events. The authors used the field study results to identify the set of input and process factors that were most strongly associated with the development of employee attitudinal outcomes. Powell and Pazos [23] also employed the I-P/M-O framework to identify the specific input and process factors that yield and sustain desired outcomes in lean manufacturing practices. There are other studies in the engineering field [24] [25], and these and various others show that the use of the I-P/M-O framework has received as much attention in the engineering field as it has in other fields of study.

\section{METHODOLOGY}

According to Bearman [26], a systematic literature review (SLR) methodology is useful for collating, reviewing, and synthesising available scholarly studies and publications on a specific topic, and so answering questions of interest by integrating the empirical evidence from all relevant studies. The SLR methodology was used in this study to ensure replicability by using transparent steps. Given the vast literature on organisational management, the SLR methodology was found to be appropriate to review the available scholarly studies specific to team-based engineering organisations.

Based on the preliminary literature review, a comprehensive list of search terms related to the supervisory role was established. The literature searches were conducted using the electronic databases Google Scholar, Web of Science, Scopus, Science-Direct, ProQuest, and EBSCO.

After employing a rigorous SLR methodology, the emerging determinants from the literature were validated. According to Borenstein [27], 'validation' refers to the testing of the process of arriving at the results, and whether the results are correct. In the context of this paper, 'validation' refers to testing whether the determinants identified from the literature were complete (i.e., that no determinant was missed) and relevant (applicable) to the specific environment of team-based engineering organisations. To validate the determinants emerging from the literature review, semi-structured interviews were found to be the most suitable method because of the flexibility they offer in allowing the interviewer to probe the participants to ensure that the list of determinants is complete and relevant to team-based engineering organisations. To collect rich data capable of validating the supervisor effectiveness determinants, an interview guideline was developed from the literature. Prior to the semi-structured interview, the interview guideline was sent to the participants so that each of them could familiarise themselves with the questions and have the opportunity to ask for clarity if any of the questions were not clearly phrased.

To select the participants, a purposive non-probabilistic expert sampling technique was employed. This technique was chosen because it allows the identification and selection of participants who are experienced in working with the supervisor effectiveness environment. It was important to select only experts for this validation process, because the purpose of the validation was to ascertain whether the list of determinants 
identified from the literature was complete, and whether it was relevant to team-based engineering organisations.

While the purposive sampling method is powerful for selecting individuals who are experts and knowledgeable about a phenomenon of interest, it is not without its critics. The most notable criticism is that this method relies on the judgement of the researcher, and this can lead to researcher bias. To mitigate this judgement-based component of purposive sampling, studies have recommended that the researcher draw up clear criteria before identifying and selecting participants [28], [29]. This clear criteria for identifying and selecting participants were drawn up beforehand and, based on the criteria, 23 experts were identified and selected as participants in the semi-structured interviews. Out of the 23 requests, seven individuals agreed to participate in the semi-structured interviews. The justification for the selected participants is given in Table 1.

Table 1: Justification for expert inclusion

\begin{tabular}{|c|l|l|l|}
\hline Expert & Organisational role & Industry & Justification for inclusion \\
\hline 1 & Section engineer & Mining & $\begin{array}{l}\text { Has } 13 \text { years of accumulated experience working with work team } \\
\text { supervisors mostly in the mining environment and has also been a team } \\
\text { supervisor while working as a plant engineer. }\end{array}$ \\
\hline 3 & Chief engineer & Power & $\begin{array}{l}\text { Currently manages supervisors of maintenance teams in the power } \\
\text { environment and has also worked as a maintenance supervisor. Expert has } \\
16 \text { years of accumulated experience. }\end{array}$ \\
\hline 4 & Technical and sales manager & Cement manufacturing & $\begin{array}{l}\text { lurrently works as a technical sales manager in a cement manufacturing } \\
\text { environment in DR Congo and has experience in supervising work-teams in } \\
\text { the manufacturing environment in Africa and other countries outside of } \\
\text { Africa. Expert has 18 years of accumulated experience. }\end{array}$ \\
\hline 5 & Components workshop supervisor & Rail maintenance & $\begin{array}{l}\text { middle-managers who are responsible for supervisors who manage the } \\
\text { maintenance activities of rolling stock components and providing safe and } \\
\text { reliable train sets for customer satisfaction. }\end{array}$ \\
\hline 6 & Engineering division manager & Maritime, USA & $\begin{array}{l}\text { Expert has supervised teams for 16 years and is still a supervisor of a } \\
\text { component workshop in a rail environment. }\end{array}$ \\
\hline 7 & Director & $\begin{array}{l}\text { Currently supervising work teams in the maritime environment in Central } \\
\text { America. Expert has a cumulative experience of } 22 \text { years }\end{array}$ \\
\hline
\end{tabular}

Various authors, through articles, book chapters, and books, have recommended a minimum sample size of five [29]-[31]. One of the many studies that followed this recommended minimum sample size is that of Ismail and Ahmad [32], in which five expert participants were interviewed to validate agent-mediated personal knowledge management processes. Based on this recommended minimum, a response of seven participants was considered acceptable for the purpose of this study.

\section{RESULTS}

A total of 931 search results were obtained from the various electronic databases. These results were screened for relevance and duplications by browsing through the authors' keywords, the topics, and the abstracts. The criterion for selection was to look for papers that deal specifically with the factors that lead to effectiveness in the supervisory role in team-based engineering organisations. After the screening process, only 111 studies were assessed further for eligibility, and this resulted in 27 studies being identified for inclusion in the SLR. Based on the themes emerging from the literature review process, a further 46 studies were identified from the literature using the emerging themes as search terms. The emerging themes were used as search terms to develop a deeper understanding of these emerging themes and to achieve a point of saturation for each emerging theme. 'Saturation' refers to the state where no new relevant theme-related data seems to emerge [33]. The themes emerging from the literature were grouped into categories using Atlas.ti. These category labels are presented in Table 2 and referred to in the rest of this document as 'determinants of supervisor effectiveness'. 
Table 2: Determinants of supervisor effectiveness

\begin{tabular}{|c|c|c|c|}
\hline \multicolumn{2}{|c|}{ Determinants } & Indicators & References \\
\hline \multirow{5}{*}{ OrC } & \multirow{5}{*}{ Organizational context } & Clarity of goals & \multirow{5}{*}{$\begin{array}{l}\text { Doolen T.L. and Hacker M.E. (2003); } \\
\text { Sundstrom et al . (1990); Zheng, } \\
\text { Yang and McLean (2010) }\end{array}$} \\
\hline & & Resource allocation & \\
\hline & & Clarity of communication & \\
\hline & & Reward \& recognition & \\
\hline & & Training availability & \\
\hline \multirow{4}{*}{ AdP } & \multirow{4}{*}{ Adaptive performance } & Problem solving & \multirow{4}{*}{$\begin{array}{l}\text { Charbonnier-Voirin et al. (2010); } \\
\text { Marques-Quinteiro et al. (2015); } \\
\text { Pulakos et al. (2002) }\end{array}$} \\
\hline & & Uncertainty & \\
\hline & & Learning & \\
\hline & & Stress withstanding & \\
\hline \multirow{3}{*}{ SkV } & \multirow{3}{*}{ Skill variety } & Technical skills & \multirow{3}{*}{$\begin{array}{l}\text { El-Baz (2010); Wilson (2016); Cohen } \\
\text { and Cohen (2012) }\end{array}$} \\
\hline & & People management & \\
\hline & & Business management & \\
\hline \multirow{3}{*}{ PoS } & \multirow{3}{*}{ Perceived organizational support } & Top management support & \multirow{3}{*}{$\begin{array}{l}\text { Eisenberger et al. (1986); Jassawala } \\
\text { and Sashittal (2011) }\end{array}$} \\
\hline & & Fairness & \\
\hline & & Working conditions & \\
\hline \multirow{4}{*}{ TfL } & \multirow{4}{*}{ Transformational leadership } & Idealised influence & \multirow{4}{*}{$\begin{array}{l}\text { Bass and Avolio (1994); Laglera et } \\
\text { al. (2013); Tanveer et al. (2018) }\end{array}$} \\
\hline & & Inspirational motivation & \\
\hline & & Intellectual stimulation & \\
\hline & & Individual consideration & \\
\hline
\end{tabular}

Five determinants emerged from the SLR, as shown in Table 2. The main studies that support these determinants are also listed in Table 2, as these studies were used to develop the validation questions for each determinant. Each determinant is discussed in the section that follows.

\section{DISCUSSION AND VALIDATION OF DETERMINANTS}

The purpose of the validation process was to validate the supervisor effectiveness determinants for completeness and relevance. Using the semi-structured interview protocol that was developed based on the determinants listed in Table 2, each participant answered questions to give their expert judgement about the relevance of each determinant, and to ascertain whether any additional considerations in the literature might have been overlooked. Each expert was asked first to rank the relevance of each indicator to team-based engineering organisations before giving a detailed explanation. The ranking was based on a five-point Likert scale ranging from 'Not relevant at all' to 'Very relevant'. The average scores are presented in Figure 3. Each of the determinants is discussed in this section, together with the validation results.

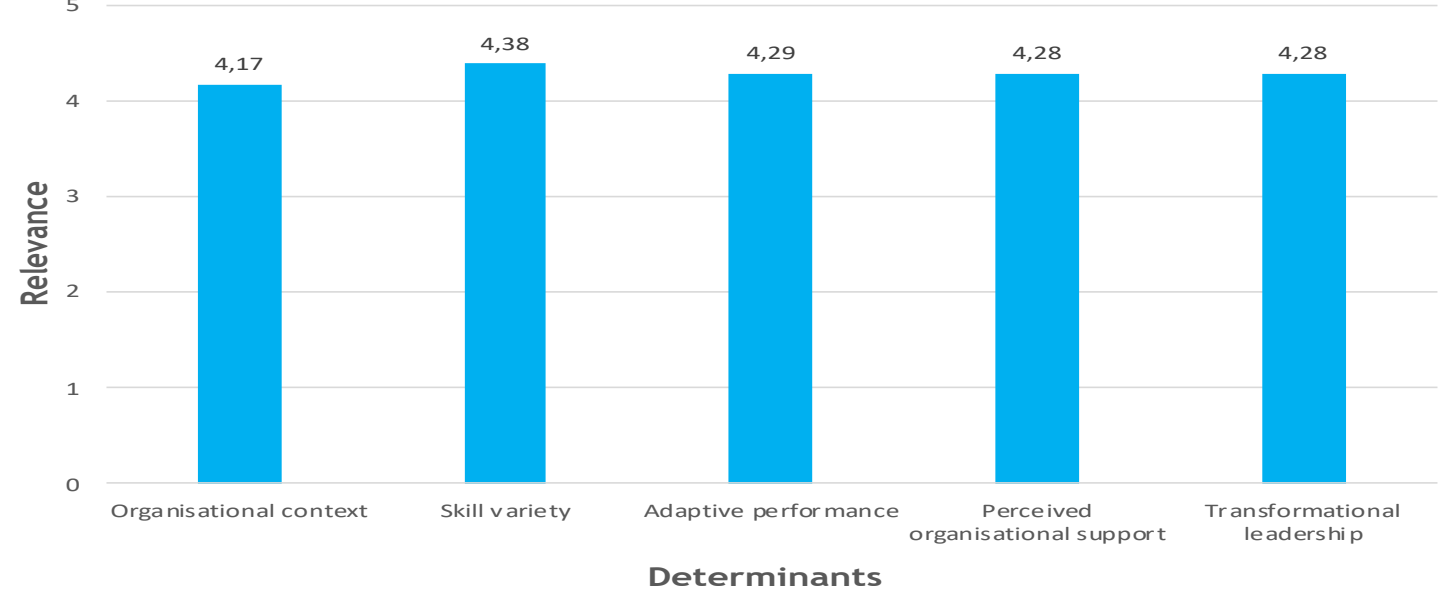

Figure 3: Validation outcomes 


\subsection{Organisational context}

Teams exist within a larger system of organisational activity and, as a result, it is important to consider the impact that this larger organisational activity has on the teams and on team management [34]. A construct used to conceptualise this organisational activity is described in the literature as organisational context (OrC). Various authors, most notably Doolen and Hacker [34], have reviewed a set of constructs that define the different aspects of OrC.

Organisational context emerged as one of the determinants for supervisor effectiveness in team-based organisations. The aspects of OrC that are relevant to supervisor effectiveness were identified from the literature, and are presented in Table 2. Clarity of goals refers to the extent to which the management processes have been successful in creating clear goals for supervisors. Ambiguity is inherent in the supervisory role in team-based organisations, and so this requires top management to set clear goals for supervisors [2], [35]. Resource allocation refers to the extent to which the management processes have been successful in providing the required resources. Clarity of communication refers to the extent to which the organisational culture supports communication between teams and between the top management and the supervisor. Reward and recognition refers to the extent to which the organisational systems provide feedback to supervisors about their work, and recognises them in the decision-making process. Training availability refers to the extent to which the organisational systems cater to the training needs of supervisors, providing specialised training for the personnel who are recruited and functioning at the supervisory level.

These key aspects of OrC that were identified as applicable to supervisor effectiveness were validated using the semi-structured interviews, and the results are shown in Figure 3.

All of the experts highlighted that all of the concepts under the organisational context determinant were relevant to team-based engineering organisations. This meant that $\operatorname{OrC}$ is relevant as a supervisor effectiveness determinant, as conceptualised and measured by the five indicators listed in Table 2. Most of the experts emphasised the importance of allocating the necessary resources, pointing out that supervisors are at the centre of where things happen, and cannot do their work if the organisation does not allocate appropriate resources, such as spares and materials.

"The supervisors are situated where the rubber hits the road and they're close to the action. So, if you don't have people who see to it that they have all the material they need, they can't do anything". Expert 3.

As observed from the literature, the experts also bemoaned the unavailability of specialised training for supervisors who were promoted from being artisans to leading their former teammates. An expert from the rail industry pointed out that their management team has embarked on a drive to provide specialised training for their supervisors to improve their effectiveness. Most experts ranked the availability of training as very relevant. One of the experts made the following observation:

"What normally will happen in our industry is that you get what we call the Peter principle, where if you're good as an artisan, you get promoted to be a supervisor, but being a good artisan doesn't mean you're a good supervisor". Expert 2.

Surprisingly, not all of the experts ranked reward and recognition as very relevant, as had been expected from the literature. Even though all of the experts agreed that reward and recognition were relevant, some felt that they were only averagely relevant. When asked whether there were any other aspects of the organisation that were essential for supervisor effectiveness, most of the experts felt that the list of concepts under the OrC determinant was complete. However, Expert two pointed out that organisational systems - such as procurement, human resources, and recruitment - were also important for supervisor effectiveness. This contribution was noted, but the concepts listed under the OrC were not modified in any way, since they were already addressed under the skill variety determinant.

\subsection{Skill variety}

'Skill variety' refers to the varied set of skills required for effectiveness in the supervisory role. The review of the literature showed a consistent agreement between scholars that a supervisor requires a varied set of skills - a balance between technical, people management, and business management skills. However, there is a notable disagreement among scholars about the correct mix of skills [9], [35]. The skill variety determinant is conceptualised as the balance between technical, people management, and business 
management skills; and these three concepts were used in the semi-structured interviews to validate the skill variety determinant, as shown in Table 2.

As illustrated in Figure 3, the experts agreed unanimously that technical skills were very relevant for supervisor effectiveness. This was somewhat different from the literature review findings, which revealed that the role of supervisor has evolved from task-related responsibilities, and so people management and business management skills are expected to be just as highly relevant, if not more so. This is corroborated by Hysong [36], who argues that technical skills do not significantly increase effectiveness; rather, they increase the perception of those who are being supervised that the supervisor is more effective.

Expert 1 pointed out that, in the mining environment, the supervisor's technical skill is the deal-breaker. He explained that the supervisor has to be able to do the artisans' work better than they can, and should be able to help them with the work whenever they need assistance. Expert 2 concurred with the sentiments of Expert 1, but added that the supervisor should be knowledgeable in the area of managing the business and using resources in a way that aligns with the strategic aims of the organisation. Expert 3 said:

"Irrespective of the technical context for the organisation, there will always be conflict, which would mean that the supervisor needs to be equipped with the people management skills to be able to supervise the team. Because remember, he or she doesn't do the work physically, themselves - maybe they do 10\%, $20 \%$ of the physical work. But $70 \%, 60 \%$ of the time, he has to supervise the execution of the tasks."

Expert 3 acknowledged the importance of technical skills by giving it a sore of 5; however, he pointed out that the supervisor spends more time in supervision work, and so people and business management skills are also relevant for supervisor effectiveness.

Based on the outcome of the semi-structured interviews with the experts, the finding from the literature review - that supervising engineering work teams effectively requires a varied set of skills - is validated. The experts also confirmed that the three sets of skills covered in the skills variety determinant captured all the skills required for supervisor effectiveness.

\subsection{Adaptive performance}

'Adaptive performance' (AdP) refers to the extent to which supervisors are able to adapt their behaviours to the requirements of work situations and new events. As conceptualised by Marques [37], there are four critical dimensions of adaptive performance that can be used to define and measure the adaptive performance of individuals and teams. These dimensions have been identified in the literature about teambased organisations as essential for the effectiveness of individuals in the supervisory role in team-based organisations. These dimensions are: problem-solving, dealing with uncertainty, openness to learning (such as learning new tasks, technologies, and procedures), and the ability to withstand stressful work conditions. The four dimensions of adaptive performance were used to validate the relevance of the adaptive performance determinant through the semi-structured interviews, with Figure 3 showing the results.

All four concepts of the adaptive performance determinant were validated by the experts as relevant for supervisor effectiveness. Uncertainty was highlighted as relevant, but not very relevant, contrary to what had been expected from the literature review findings. As discussed in the literature review sections, various authors pointed out that the role of a supervisor is often ambiguous, and so it requires the individual employed in this role to be able to deal with uncertainty. The interviewed experts agreed with this finding, but did not equate the importance of being able to deal with uncertainty with that of problem-solving or the ability to withstand stressful work conditions. Expert 7 is quoted below:

"The amount of pressure that supervisors work requires them to be able to work under stressful conditions and be able to learn on the job... You know, something blows up and they need to run around. That affects their performance sometimes, if they don't have the correct support and cannot absorb the pressure. A high-stress environment will affect their performance if they cannot withstand stress."

None of the concepts under the adaptive performance determinant was rated below the averagely relevant score. The experts agreed that these four concepts were relevant for effectiveness in the role of supervision, and no extra concept was added under the AdP determinant.

\subsection{Perceived organisational support}

'Perceived organisational support' (PoS) refers to the extent to which a supervisor feels supported, based on the concern and support they receive from the organisation. This research draws from organisational 
support theory to conceptualise a determinant that represents the supervisors' perception of how much the organisation values their contribution and cares about their well-being [38].

Supervisors in engineering organisations need a support system to enable them to manage their teams and improve their value-adding work on the shop floor [39] [40]. Thamhain [41] found that, specifically in technology-intensive teams, top management support is one of the critical success factors that leads to supervisory effectiveness. Jassawalla and Sashittal [4] found that teams led by supervisors who receive support from their senior managers in turn show more collaborative behaviours. Top managers are wellpositioned to facilitate and provide the infrastructure and technology that is mandatory for supervisor effectiveness and technology transfer. The antecedents of PoS are top management support, fairness, and working conditions. These were used as indicators of the PoS determinant [42]. The three indicators of PoS were used in the semi-structured interviews; the results are shown in Figure 3.

As illustrated in Figure 3, all three concepts covered under the PoS determinant were judged by the experts to be almost equally relevant. The interviews revealed that supervisors have to be in a position where they are assured that their manager will support them, especially when it comes to matters relating to team members. This assertion by the experts supports the findings from the literature, particularly the work of Thamhain [41], who found that, in technology-intensive organisations, top management support is one of the critical success factors for effectiveness. Expert 6 highlighted the fact that one of the key performance indicators for middle management is how they manage and support the supervisor, and added that this fact on its own is an indicator of how critical the support given to the supervisor is.

The relevance of the working conditions also came out strongly from the validation interviews, with most experts rating it 5 , and explaining that even the most driven supervisor will feel deflated if the working conditions are constantly against them. Based on the experts' judgement, the PoS determinant was relevant for supervisor effectiveness, and the concepts covered under this determinant were exhaustive and complete.

\subsection{Transformational leadership}

The concept of 'transformational leadership' ( $T f L)$ was introduced in two seminal works [43] [44]. Various authors have made contributions in developing the concept of TfL and investigating its relationship with other organisational concepts - such as, but not limited to, conflict management [45], engineering leadership [46], health and safety [47], project management [48], and team effectiveness [49]. Most notably, Bass and Avolio [50] are known to be the leading authors in the development of TfL. They conceptualise leadership in general to consist of three categories: transformational leadership, transactional leadership, and laissez-faire leadership. TfL encompasses four dimensions: idealised influence (referring to the behaviour of the leader that followers intend to imitate - formerly known as charismatic leadership [44]), inspirational motivation (referring to the ability of the leader to set goals and motivate the team), intellectual stimulation (referring to the leader's ability to consider different points of view when addressing a problem, and challenging employees to think about problems in new ways) and, last, individualised consideration (referring to the leader's ability to acknowledge an individual's effort and achievement of specified goals, and to take into account the characteristics of each person [46], [50], [51].

Supervisors are leaders in their own right, as they are often tasked to use their influence to ensure that work is done to achieve the desired results [45], [47], [52]. Tanveer et al. [52] conducted a study focusing on supervisors working in the textile industry. Their study investigated various leadership styles of supervisors; they found that supervisors with a high degree of transformational leadership are more effective, as they are able to provide satisfaction and motivation for their teams. This finding is in line with that of Oswald and Lingard [47], who focused their study on supervisors in the construction environment. They found that supervisors can be more effective by adopting transformational behaviours such as providing workers with feedback and empowering workers to participate in decision-making processes. The authors added that this could even enhance the safety performance in the construction industry. In addition to the relationship between TfL and supervisor effectiveness, Charbonnier, Akremi and Vandenberghe [53] found that there is a link between TfL and adaptive performance.

Based on the semi-structured interviews, the contributions from the experts regarding the four concepts of transformational leadership were similar to those found in the literature. The experts felt that the concepts covered under this determinant were complete and relevant for effectiveness in supervision.

Figure 3 shows that all the concepts under the transformational leadership determinant were judged by the experts to be relevant for effectiveness. This result was expected, based on the emphasis from various 
authors in the literature on the importance of leadership and the role that leadership plays in successful organisations. Expert 1 explained the influence that the supervisor has on his team in the mining environment in these words:

"The supervisor has a 100\% influence on his team. So, what he does becomes the culture. If he cuts corners in safety, the team will cut corners. If he doesn't take excuses and he doesn't tolerate unsafe working behaviour, or any form of bad behaviour, you'll see, the team will also change."

\section{CONCLUSIONS}

Even though the supervisory role has been explored in several academic studies, very few studies have attempted to examine empirically the exact determinants that lead to supervisor effectiveness, particularly in team-based engineering organisations. This paper defined a supervisor effectiveness construct using the I-P/M-O theoretical framework. Following this framework, the supervisor effectiveness construct is an output that is determined by other factors (determinants) that are either inputs or mediators.

Two independent determinants (organisational context and transformational leadership) emerged from the systematic review of the literature and were validated for relevance through the semi-structured interviews. These two determinants are prerequisites for enabling the supervisor to be effective in their role, and are shown as inputs in Figure 4. Three more determinants emerged as prerequisites for supervisor effectiveness, mediating the relationship between the independent determinants and the supervisor effectiveness construct. The framework presented in Figure 4 also shows the causal relationships between the determinants represented by the arrows; these relationships are based on earlier work by the authors of the present study [54].

\section{IMPLICATIONS FOR ENGINEERING MANAGERS}

Team effectiveness has received increasing attention in the literature. However, a limited number of studies address the effectiveness of team supervisors in the specific context of engineering organisations. There is limited research that focuses on the individuals managing work teams in these organisations and what determines their effectiveness. This study has identified five supervisor effectiveness determinants, with two noteworthy implications for engineering managers. First, creating and developing training programmes for team supervisors is notoriously difficult. The results of this study could be used by engineering managers to guide the content development of supervisor training initiatives. Second, the results of this study could be used by engineering managers in recruiting suitable personnel for a supervisory role in team-based engineering organisations.

\section{LIMITATIONS AND FUTURE LINES OF RESEARCH}

The findings of this study are limited to team-based engineering organisations. As pointed out in the introduction, the engineering environments from which the study drew included construction, the power sector, transportation, chemical industries, manufacturing, and production. A further limitation of the findings pertains to the criticism raised by Ilgen [19] of the I-P-O frameworks in general - that they somehow limit research by implying a single-cycle linear path. In line with this criticism, the model presented in this study implies a linear progression of main effect influences, moving from the two independent determinants through to the supervisor effectiveness construct. However, recent research suggests a move beyond this point, to quantifying the causal relationships. The relationships presented in the resultant model of this study have not been quantified. It is envisioned that the future phases of this study will employ causal modelling techniques that are capable of simultaneously testing and quantifying multiple independent and dependent constructs. 


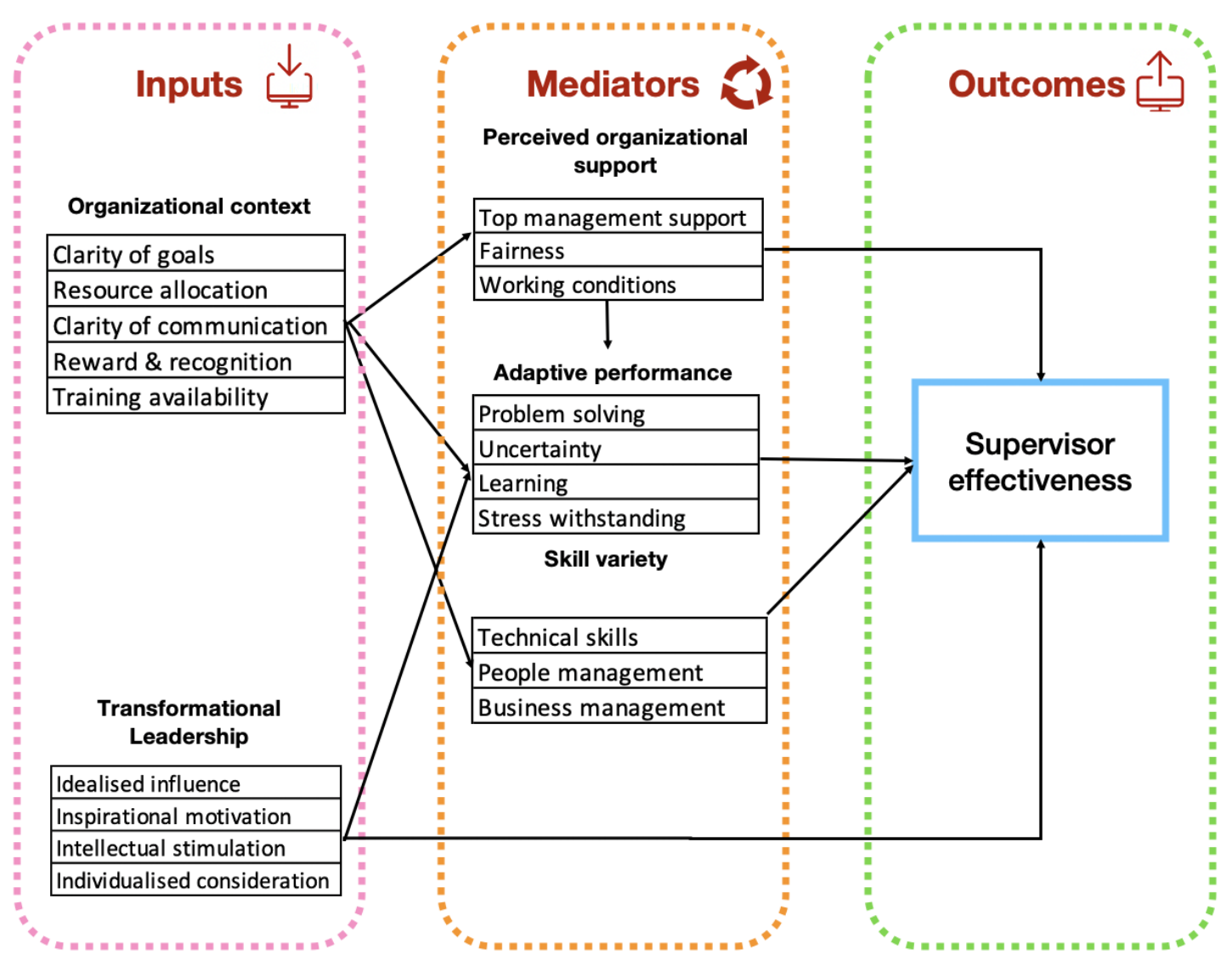

Figure 4: Showing the I-(P)M-O framework with the determinants

\section{REFERENCES}

[1] Powell, A.W. \& Pazos, P. 2017. Building high-performing autonomous teams in complex manufacturing settings: A naturalistic research approach. Eng. Manag. J., 29(3), pp. 206-219.

[2] Doolen, T.L., Hacker, M.E. \& Van Aken, E.M. 2003. The impact of organizational context on work team effectiveness: A study of production team. IEEE Trans. Eng. Manag., 50(3), pp. 285-296.

[3] Ingvaldsen, J.A. \& Benders, J. 2020. Back through the back door? On removing supervisors to reduce hierarchy. Balt. J. Manag., 15(3), pp. 473-491.

[4] Jassawalla, A.R. \& Sashittal, H.C. 2001. The role of senior management and team leaders in building collaborative new product teams. Eng. Manag. J., 13(2), pp. 33-39.

[5] Harris, C.L. \& Beyerlein, M. 2003. Team-based organization: Creating an environment for team success. In $M$. West, K. Smith \& D. Tjosvold (Eds.), International handbook of organizational teamwork and cooperative working. Chichester: Wiley.

[6] Clemmer, J. 2012. Leadership competency models: Why many are failing and how to make them flourish. https://www.clemmergroup.com/articles/leadership-competency-models-many-failing-make-flourish/ Date accessed: 09/09/2019

[7] Davis, K. 1967. Human relations at work: The dynamics of organizational behavior, 3rd ed. New York: McGrawHill.

[8] Huo, M.L. \& Boxall, P. 2017. Lean production and the well-being of the frontline manager: The job demandsresources model as a diagnostic tool in Chinese manufacturing. Asia Pacific J. Hum. Resour., 55(3), pp. 280-297.

[9] Artz, B.M., Goodall, A.H. \& Oswald, A.J. 2017. Boss competence and worker well-being. Ind. Labor Relations Rev., 70(2), pp. 419-450.

[10] Fleishman, E.A. 1953. The description of supervisory behavior. J. Appl. Psychol., 37(1), pp. 1-6.

[11] Mintzberg, H. 1975. The manager's job: Folklore and fact. Harv. Bus. Rev., 53(4), pp. 49-61.

[12] Heyel, C. (ed.). 1984. The foreman/supervisor's total job. In Foreman/supervisor's handbook, pp. 3-21. New York: Van Nostrand Reinhold Company.

[13] Op de Beeck, S., Wynen, J. \& Hondeghem, A. 2018. Explaining effective HRM implementation: A middle versus first-line management perspective. Public Pers. Manage., 47(2), pp. 144-174.

[14] Magpili, N.C. \& Pazos, P. 2018. Self-managing team performance: A systematic review of multilevel input factors. Small Group Research, 49(1), pp. 3-33. 
[15] Bahn, S. 2013. Transformational leaders? The pivotal role that supervisors play in safety culture. Int. J. Train. Res. , 11(1), pp. 17-26.

[16] McGrath, J.E. 1964. Social psychology: A brief introduction. New York: Holt, Rinehart and Winston.

[17] Hackman, J.R. \& Morris, C.G. 1975. Group tasks, group interaction process, and group performance effectiveness: A review and proposed integration. Adv. Exp. Soc. Psychol., 8, pp. 45-99.

[18] Dulebohn, J.H. \& Hoch, J.E. 2017. Virtual teams in organizations. Hum. Resour. Manag. Rev., 27(4), pp. 569-574.

[19] Ilgen, D.R., Hollenbeck, J.R., Johnson, M. \& Jundt, D. 2004. Teams in organizations: From input-process-output models to IMOI models. Annu. Rev. Psychol., 56(1), pp. 517-543.

[20] Kozlowski, S.W.J. \& Bell, B.S. 2003. Work groups and teams in organizations. In Handbook of Psychology, $2^{\text {nd }}$ ed., pp. 333-375.

[21] Mathieu, J.E., Gallagher, P.T., Domingo, M.A. \& Klock, E.A. 2019. Embracing complexity: Reviewing the past decade of team effectiveness research. Annu. Rev. Organ. Psychol. Organ. Behav., 6(1), pp. 17-46.

[22] Farris, J.A., Van Aken, E.M., Doolen, T.L. \& Worley, J. 2009. Critical success factors for human resource outcomes in Kaizen events: An empirical study. Int. J. Prod. Econ., 117(1), pp. 42-65.

[23] Powell, A. \& Pazos, P. 2010. Research model for measuring performance and sustainability of high-variety, lowvolume lean manufacturing. In A. Johnson and J. Miller (eds), Proceedings of the 2010 Industrial Engineering Research Conference, pp. 6-9.

[24] Chen, C.H., Ho, Y.H. \& Chan, L.J. 2010. Team implicit coordination in manufactory industry: Assessing the mediating role of empowering leadership and team efficacy. 3CA 2010 - 2010 Int. Symp. Comput. Commun. Control Autom., 2, pp. 459-462.

[25] Hsu, B.F., Wu, W.L. \& Yeh R.S. 2007. Personality composition, affective tie and knowledge sharing: A team level analysis. Portl. Int. Conf. Manag. Eng. Technol., pp. 2583-2592.

[26] Bearman, M. and \& Dawson, P. 2013. Qualitative synthesis and systematic review in health professions education. Med. Educ., 47(3), pp. 252-260.

[27] Borenstein, D. 1998. Towards a practical method to validate decision support systems. Decision Support Systems, 23(3), pp. 227-239.

[28] Sharma, G. 2017. Pros and cons of different sampling techniques. Int. J. Appl. Res., 3(7), pp. 749-752.

[29] Saunders, M., Lewis, P. \& Thornhill, A. 2012. Research methods for business students, $6^{\text {th }}$ ed. New York, Harlow: Pearson.

[30] Dudovskiy, J. 2018. The Ultimate Guide to Writing a Dissertation in Business Studies: A Step-by-Step Assistance.

[31] Dworkin, S.L. 2012. Sample size policy for qualitative studies using in-depth interviews. Archives of Sexual Behavior, 41, pp. 1319-1320.

[32] Ismail, S. \& Ahmad, M.S. 2012. Emergence of personal knowledge networks in agent-mediated PKM processes: A qualitative analysis in Malaysian context. 2012 Int. Conf. Comput. Inf. Sci., 1, pp. 72-78, 2012.

[33] Strauss, J. \& Corbin, A. 1998. Basics of qualitative research: Techniques and procedures for developing grounded theory. Thousand Oaks, CA: Sage Publications.

[34] Doolen, T.L. \& Hacker, M.E. 2003. Assessing organizational context in team-based organizations. Adv. Interdiscip. Stud. Work Teams, 9, pp. 67-90.

[35] Hales, C. 2005. Rooted in supervision, branching into management: Continuity and change in the role of first-line manager. J. Manag. Stud., 42(3), pp. 471-506.

[36] Hysong, S.J. 2008. The role of technical skill in perceptions of managerial performance. J. Manag. Dev., 27(3), pp. 275-290.

[37] Marques-Quinteiro, P., Ramos-Villagrasa, P., Passos, A.M. \& Curral, L. 2015. Measuring adaptive performance in individuals and teams. Team Perform. Manag. An Int. J., 21(7/8), pp. 339-360.

[38] Eisenberger, R., Huntington, R., Hutchison, S. \& Sowa, D. 1986. Perceived organizational support. J. Appl. Psychol., 71(3), pp. 500-507.

[39] Liu, L. \& McMurray, A.J. 2004. Frontline leaders: The entry point for leadership development in the manufacturing industry. J. Eur. Ind. Train., 28(2), pp. 339-352.

[40] Shah, H. (ed.) \& Nowocin, W. (assoc. ed.) 2015. A guide to the engineering management body of knowledge, $4^{\text {th }}$ ed. The American Society for Engineering Management. USA

[41] Thamhain, H.J. 2011. Critical success factors for managing technology-intensive teams in the global enterprise. Eng. Manag. J., 23(3), pp. 30-36.

[42] Rhoades, L. \& Eisenberger, R. 2002. Perceived organizational support: A review of the literature. J. Appl. Psychol., 87(4), pp. 698-714.

[43] Burns, J. 1978. Leadership. New York: Harper \& Row.

[44] House, R.J. 1977. A 1976 theory of charismatic leadership. Working paper series 76-06. Toronto, Ontario.

[45] Hunitie, M. 2016. A cross-sectional study of the impact of transformational leadership on integrative conflict management. Asian Soc. Sci., 12(5), pp. 47-53.

[46] Laglera, J.L.M., Collado, J.C. \& De Oca, J.A.M.M. 2013. Effects of leadership on engineers: A structural equation model. Eng. Manag. J., 25(4), pp. 7-16.

[47] Oswald, D. \& Lingard, H. 2019. Development of a frontline H\&S leadership maturity model in the construction industry. Saf. Sci., 118(April), pp. 674-686.

[48] Pretorius, S., Steyn, H. \& Bond-Barnard, T.J. 2018. Leadership styles in projects: Current trends and future opportunities. South African J. Ind. Eng., 29(3) Special Edition, pp. 161-172.

[49] Özaralli, N. 2003. Effects of transformational leadership on empowerment and team effectiveness. Leadersh. Organ. Dev. J., 24(6), pp. 335-344.

[50] Bass, B.M. \& Avolio, B.J. (eds). 1994. Improving organizational effectiveness through transformational leadership. Thousand Oaks, CA: Sage. 
[51] Jauhari, H., Singh, S. \& Kumar, M. 2017. How does transformational leadership influence proactive customer service behavior of frontline service employees? Examining the mediating roles of psychological empowerment and affective commitment. J. Enterp. Inf. Manag., 30(1), pp. 30-48.

[52] Tanveer, Y., Jiayin, Q., Akram, U. \& Tariq, A. 2018. Antecedents of frontline manager handling relationship conflicts. Int. J. Confl. Manag., 29(1), pp. 2-23.

[53] Charbonnier-Voirin, A., El Akremi, A. \& Vandenberghe, C. 2010. A multilevel model of transformational leadership and adaptive performance and the moderating role of climate for innovation. Gr. Organ. Manag., 35(6), pp. 699-726.

[54] Zincume, P.N. \& Jooste, J.L. 2019. Determinants towards a frontline supervisor effectiveness model for engineering team-based organizations. In Proceedings of the International Annual Conference of the American Society for Engineering Management (ASEM)., pp. 1-10. 